\title{
Randomized multicenter follow-up trial on the effect of radiotherapy for plantar fasciitis (painful heels spur) depending on dose and fractionation - a study protocol
}

\author{
Henrik Holtmann ${ }^{1,2}$, Marcus Niewald $^{1 *}$, Benjamin Prokein ${ }^{1}$, Stefan Graeber ${ }^{3}$ and Christian Ruebe
}

\begin{abstract}
Background: An actual clinical trial showed the effect of low dose radiotherapy in painful heel spur (plantar fasciitis) with single doses of 1.0 Gy and total doses of 6.0 Gy applied twice weekly. Furthermore, a lot of animal experimental and in vitro data reveals the effect of lower single doses of 0.5 Gy which may be superior in order to ease pain and reduce inflammation in patients with painful heel spur. Our goal is therefore to transfer this experimentally found effect into a randomized multicenter trial.

Study design/methods: This was a controlled, prospective, two-arm phase III-multicenter trial. The standard arm consisted of single fractions of $1.0 \mathrm{~Gy}$ applied two times a week, for a total dose of $6.0 \mathrm{~Gy}$ (total therapy time: 3 weeks). The experimental arm consisted of single fractions of 0.5 Gy applied 3 times a week, for a total dose of 6.0 Gy (total therapy time: 4 weeks). Following a statistical power calculation, there were 120 patients for each investigation arm. The main inclusion criteria were: age $>=40$ years, clinical and radiologically diagnosed painful heel spur (plantar fasciitis), and current symptoms for at least 6 months. The main exclusion criteria were: former local trauma, surgery or radiotherapy of the heel; pregnant or breastfeeding women; and a pre-existing severe psychiatric or psychosomatic disorder.
\end{abstract}

Methods: After approving a written informed consent the patients are randomized by a statistician into one of the trial arms. After radiotherapy, the patients are seen after six weeks, after twelve weeks and then every twelve weeks up to 48 weeks. Additionally, they receive a questionnaire every six weeks after the follow-up examinations up to 48 weeks. The effect is measured using the visual analogue scale of pain (VAS), the calcaneodynia score according to Rowe and the SF-12 score. The primary endpoint is the pain relief three months after therapy. Patients of both therapy arms with an insufficient result are offered a second radiotherapy series applying the standard dose (equally in both arms). This trial protocol has been approved by the expert panel of the DEGRO as well as by the Ethics committee of the Saarland Physicians' chamber.

Trial registration: Current trial registration at German Clinical Trials Register with the number DRKS00004458

Keywords: Painful heel spur, Plantar fasciitis, Low dose radiotherapy, Randomized multicenter trial

\footnotetext{
* Correspondence: Marcus.Niewald@uks.eu

'Department of Radiotherapy and Radiooncology, Saarland University

Hospital, Kirrberger Str. 1, D-66421 Homburg, Germany

Full list of author information is available at the end of the article
} 


\section{Background Principles}

The painful heel spur was first described by Plettner et al. [1] summarizing radiological findings of exostoses situated at the plantar part of the calcaneus or at the insertion point of the plantar aponeurosis. Various authors give values for the incidence of 8 to $88 \%$ of an unselected population [2-4]. Risk factors described are old age, obesity, and foot or leg deformities. Histopathological findings are fibroostosis promoted by mechanical stress to the plantar aponeurosis, slowly and continuously growing into its insertion region [5]. In a more chronical stage of the disease, the degenerative changes cause a local inflammation of the plantar aponeurosis (plantar fasciitis), which should be well differentiated from - for example - rheumatoid arthritis.

\section{Clinical symptoms}

Radiological diagnosed heel spurs often are completely asymptomatic. $16 \%$ of the patients with painful heel spurs have local pain getting worse over weeks to months under the heel, which can further extend to the foot or the lower limb. Local pressure to the medial edge of the calcaneus may be painful [5]. To our own experience, most of the symptomatic patients cannot stand or walk for a long time, the pain may be even worse during the first minutes of rest after a walk.

\section{Radiological findings}

Conventional lateral $\mathrm{x}$-rays of the calcaneus are gold standard in the diagnosis of a heel spur. They show a calcified spur at the inferior side of the calcaneus. The intensity of pain does not correlate to the radiological size of the spur. Additionally a local ultrasound examination can be performed in order to examine the swelling and irritation of the plantar fascia. A bone scan may be positive showing local inflammation which remits after successful therapy. A good diagnostic alternative to the scintigraphy seems to be the MR imaging because of its superior soft tissue contrast and good anatomical resolution. Typical in MR imaging is a thickening of the fascia and a surrounding soft tissue edema. In contrastmedium enhanced sequences intratendinous signal alterations of the fascia are often found.

\section{Conventional therapy methods}

Ice, heat, ultrasound, radiofrequency, laser beams and extracorporal shock wave therapy have been applied, all of them with confined clinical success. Steroids and local anesthetics injected into the plantar fascia and oral analgetic medication (NSAID) are often prescribed. Immobilization of the foot using special splints and adjustable shoes were applied. Physiotherapy was performed [2,3]. Iontophoresis using dexamethasone was found to be superior to iontophoresis with placebo $(\mathrm{NaCl})$ [6]. Extracorporal shock wave therapy yielded a complete pain relief in up to $68 \%$ of the patients [7]. A randomized trial published by Batt et al. [8] showed that better results were recorded by adding local immobilization of the foot in maximum dorsal flexion during night to a standard therapy (NSAID, splints) compared to this standard therapy alone. According to Powell et al. [9], a splint applied immediately after diagnosis was as effective as an application one month later. In further randomized trials mechanical therapy using ortheses was found better than application of local analgesics only, silicon shoe inserts were found superior to other shoe adjustments [10], functional foot ortheses were found to be more advantageous than simple heel splints [11]. Most of these methods and their results have been summarized in an actual Cochrane review [12].

\section{Surgery}

It is general consensus that patients will only undergo surgery in case conservative therapy methods have not yielded sufficient pain relief. Heider et al. [13] report good to excellent results in 26 out of 28 feet after open surgery. Favourable results were recorded as well using endoscopic release of the plantar fascia [14]. Nevertheless, complications like fractures of the calcaneus [15] as well as negative biomechanical consequences of plantar fascia relief have been reported [16].

\section{Radiotherapy - experimental data}

The anti-inflammatory effect of radiation therapy has been known for a long time and has been reported in numerous publications. Nevertheless, the exact ultrastructural mechanism is still unclear. Some of the more ancient models are discussed in [17-20].

In animal experiments, Steffen et al. noticed antiinflammatory effects of low-dose radiotherapy (6Gy) on antigen-induced arthritis in rabbits [21]. Hildebrandt et al. have shown that low-dose radiation effects can be explained by an influence on molecular mechanisms and inflammation mediators [22-24]. New in-vitro investigations by Hildebrandt et al. 2003 and Rödel et al. 2002 $[25,26]$ show a reduced iNOS protein expression and NO-production in macrophages. Latter investigation could also point that single doses of $0.3-0,5$ Gy lead to a local maximum of apoptosis in macrophages and a reduced E-selectin-presentation on endothelium cells combined with an enhanced expression of TGF $\beta 1$ [26]. Hildebrand could also show in vitro that depending on modulation of cytokine-stimulated E-selectin-presentation leukocytes could less adhere to endothelium especially with single doses of 0.3-0.6 Gy. This finding also underlines the anti-inflammatory effect of low-dose therapy [27]. Additionally Gaipl et al. (2009) revealed a maximum of activity-induced cell death in polymorphnuclear cells 
by use of single doses of 0.3 Gy in radiotherapy [28]. Further anti-inflammatory effects of low-dose radiotherapy seem to be a reduced CCL-20-chemokine-expression, a reduced adhesion of granulocytes to endothelium cells and an enhanced activity of AP-1 DNA ligation strength $[29,30]$. An actual review article points out the induction of expression of the X-linked inhibitor of apoptosis and TGF $\beta 1$ and the reduced expression of E- and L-selectin, Interleukin-1 and CCL20 through macrophages and polymorphnuclear cells using single doses between 0.5 and 0.7 Gy [31]. Another new review article shows additionally high levels of hemioxigenase 1 (HO-1) and heat shock protein 70 (HSP 70) with maximum single doses of 0.5 Gy [32].

\section{Radiotherapy - clinical results}

Numerous retrospective trials have shown that low-dose radiotherapy for painful heel spur has a good analgesic effect, pain relief has been noticed in $65-90 \%$ of the patients $[17,20,33-36]$. However, a certain placebo effect is still under discussion [33]. Goldie et al. examined this effect in 399 patients with painful conditions of the locomotor system. They found a response in $60 \%$ of the patients whether irradiated or not; these results made the effect of radiotherapy questionable [37]. The trial, however, has been criticized because of missing clearly defined endpoints: furthermore the therapy was started in an acute stage of the diseases and the authors did not wait for spontaneous pain remissions. In the meantime, several more modern trials have shown the analgetic effect of radiotherapy. Seegenschmiedt et al. [2] performed a randomized trial treating 141 patients (170 heels) for painful heel spur using orthovoltage, comparing three radiotherapy schedules: $1 \mathrm{~Gy} /$ fraction up to $12 \mathrm{~Gy}$, $0.3 \mathrm{~Gy} /$ fraction up to $3 \mathrm{~Gy}$ and $0.5 \mathrm{~Gy} /$ fraction up to 5 Gy. The overall complete pain relief was reported in $67-72 \%$ of the patients. The best results were seen after a total dose of $5 \mathrm{~Gy}$. These results were confirmed by Schäfer et al. using a telecobalt machine, they achieved a complete pain relief in 58\% [33]. Heyd et al. used $6 \mathrm{MV}$ photon beams of a linear accelerator, they noticed a frequency of pain relief of $69 \%$ [4]. The same author group published a prospective randomized trial recently [38] comparing the effect of a total dose of 3 Gy (single fraction 0.5 Gy twice weekly) to that of a total dose of $6 \mathrm{~Gy}$ (single fraction 1 Gy twice weekly). Radiotherapy was reported very efficient however a dependency from dose could not be noticed. Mücke et al. looked for prognostic factors for pain relief in a multicenter trial [39]. They found an overall response in $60.9 \%$. Significant favourable prognostic factors for pain relief were a patient's age over 58 years, the use of megavoltage techniques and the number of therapy series required. Niewald et al. showed in actual prospective study that a total dose of 6 Gy with single doses of 1 Gy twice weekly is much more effective than a total dose of 0.6 Gy with single doses of 0.1 Gy concerning analgetic effect and showed that a total doses of 6 Gy makes this effect durable for at least 1 year [40]. After the start of this trial, Ott et al. [41] published their trial comparing the effect of six single doses of 1Gy (total dose 6 Gy) to six single doses of $0.5 \mathrm{~Gy}$ (total dose 3Gy). They found no difference between the arms.

\section{Radiotherapy - side effects and risks}

Physicians of other specialities sometimes refuse to refer patients to radiotherapy because of the fear of local side effects such as impairment of gonad function or induction of malignancies. Neither local toxicity nor tumour induction have been reported yet $[34,42,43]$. The dose to the gonads is comparable to that after radiodiagnostic interventions [20,44-46].

\section{Radiotherapy - conclusion}

Summarizing the data taken from the literature it can be concluded that low-dose radiotherapy for painful heel spur with total doses ranging from 3-12 Gy is effective in the vast majority of patients and the side effects are negligible. However, a placebo effect cannot be excluded totally. Thus, randomized trials (like the present one) using defined criteria and scores are necessary [4].

Nevertheless, outside Europe there is a general reluctance against radiotherapy for benign disease. One reason may be that trials comparing conservative approaches, radiotherapy and surgery are very rare.

Much more important to our current trial is, however, to translate the experimental findings that lower single doses may be more advantageous than higher ones into the clinic comparing two patient groups with the same total dose and different fractionation schedules (1.0 Gy vs. 0.5 Gy).

\section{General therapy remarks}

At the moment a lot of competing therapy approaches for painful heel spur are processed. One can summarize them to conventional/conservative approaches, radiotherapy and surgery. Up to now a lack of definite evidence is still existing which method to choose. Additionally and despite all experimental and clinical findings concerning radiotherapy for painful heel spur a general reluctance against radiotherapy is exsisting unfortunately.

\section{Study design \\ Eligibility criteria \\ Inclusion criteria}

- clinical evidence of painful plantar heel spur with an anamnesis during $\geq 6$ month

- radiological proof of the spur (in conventional radiography)

- typical clinical symptomatic with tenderness on palpation at medial tuber calcanei 
- typical functional deficit: impairment of painless walking distance

- Karnofsky performance index $\geq 70 \%$

- age $\geq 40$ years

- written informed consent

\section{Exclusion criteria}

- previous radiotherapy and/or trauma to the foot region (i.e. fracture, tendon rupture)

- rheumatic, arterial or venous diseases, manifest lymphatic edema of the concerned foot/leg

- pregnancy, breastfeeding (regulatory reasons)

- severe psychiatric disorder

- statutory maintenance in medical affairs by relatives

\section{Informed consent}

Before enrolment into the study, an informed consent is to be obtained from all patients after detailed information and explanations concerning:

- the positive and negative aspects of the therapy (i.e. toxicity),

- alternative therapy methods,

- data protection issues,

- schedule of the study (follow-up examinations, time frame, etc.),

- autonomy of choice in participating into the study, all the time possibility to withdraw the consent without the need to communicate special reasons

\section{Initial diagnosis}

- Obligate: standardized anamnesis, clinicalorthopedic examination, lateral $\mathrm{x}$-ray imaging of metatarsus and heel with diagnosis of heel spur in the region of tuberculum mediale calcanei at the dorsal insertion of the plantar aponeurosis

- Facultative: Ultrasound illustrating inflammation of plantar aponeurosis, bone scan in case of negative $\mathrm{x}$-ray, MR-tomography to demonstrate the process of plantar fasciitis or detect further symptoms (i.e. bone marrow edema).

\section{Therapy protocol}

After recording anamnesis, clinical-orthopedic investigation, radiographic confirmation of the diagnosis, checking eligibility criteria and written informed consent, filling in the SF-12-, Calcaneodynia- and VAS score forms, patients are randomly assigned to either Arm A or B of this study.
- Arm A (standard dose): Total dose of 6Gy, single fractions of 1 Gy applied two times a week over three weeks (either Monday/Thursday or Tuesday/Friday)

- Arm B (experimental dose): Total dose of 6 Gy, single fractions of 0.5 Gy applied three times a week over 4 weeks (Monday/Wednesday/Friday)

- Consequently, the gap between the fractions within a week is one to two days.

- Follow-up examinations are performed every six weeks after radiotherapy filling in the Calcaneodynia-Score, SF-12 questionnaire and VAS-score. On weeks 6, 12, 24, 36 and 48 after radiotherapy, the patients get an additional physical examination, on weeks $18,30,42$ they only receive the questionnaires.

In case of persisting or aggravating origin symptoms despite radiotherapy minimum twelve weeks after radiotherapy patients in both arms are offered a second treatment with the standard fractionated dose. The ideal time point will be chosen by the patient and the local radiooncologist together. Results of these patients are categorized as unsatisfactory and censored beyond the leaving date of the patient. Patients wishing the second therapy series later than 12 weeks after therapy will be taken into account in the final analysis.

After follow-up examination of all 240 patients (120 per arm) for 48 weeks the study will be closed and the final data analysis will be performed. Interim analyses will be performed after enrolment of 120 and 180 patients. In case of significantly different results in the groups or the publication of practice changing results from other authors which lead an ethical reappraisal of this trial the randomization of new patients will be stopped and the already randomized patients will get their follow-up examinations up to 48 weeks.

The use of analgesic drugs and physiotherapy is allowed during the trial. These will be recorded and taken in to account in the final analysis. Patients having been treated by shock wave therapy or surgery will be excluded from the analysis.

\section{Randomization and statistics}

Randomization is performed as a block randomization by the statistician. Patients are assigned randomly to one of the therapy arms by equal possibility for randomization for both arms.

According to a previous trial published by Niewald et al. (40) and an actual statistical calculation before beginning this study 120 patients are required in each arm and have to be evaluated over 48 weeks (inclusive a drop-out rate of $10 \%$ of the patients) in order to detect a difference of $15 \%$ in VAS and Calcaneodynia-Score with a power of $80 \%$ (error probability of 5\%). 
Statistics (primary and secondary endpoints) are performed using the MEDLOG software package (Fa. Parox, Münster) after observing the patients for 12 and 48 weeks and are controlled by the statistician.

\section{Primary endpoints (measured at 12 and 48 weeks after therapy)}

- SF-12 sum score $[47,48]$

- Calcaneodynia sum score $[2,49]$

- VAS self-assessment-score

The endpoints will be measured 12 and 48 weeks after radiotherapy, the results will be compared.

\section{Secondary endpoints}

- SF-12 single score

- Calcaneodynia single score

- Event-free interval

\section{Radiotherapy methods}

Radiotherapy is performed under orthovoltage conditions $(200-250 \mathrm{kV})$ or high voltage conditions using a cobalt unit or high energy photons of linear accelerators (up to 6 MV without bolus, $10 \mathrm{MV}$ with a bolus of $1 \mathrm{~cm}$ ).

For orthovoltage therapy, a plantar direct field with tissue equivalent bolus material affixed around the heel is used ('Essen technique'). The dose should be standardized to a fix reference point (i.e. in $5 \mathrm{~mm}$ tissue depth).

For cobalt units or linear accelerators isocentric lateral parallel opposing portals are used (isocenter: center of calcaneus).

The dose is computed either by individual calculation or by depth- dose curves/charts of the therapy machines. The target volume should involve the calcaneus, plantar aponeurosis and the pain point including a safety margin of $2 \mathrm{~cm}$. Gonads have to be shielded as well as possible.

\section{Quality assurance}

Methods to ensure quality are especially:

- Questionnaires are signed for accuracy by physician and physicist

- Visiting and personally initiation of all participating centers. Participating centers will additionally been asked to send $\mathrm{x}$-rays, portal imaging pictures and therapy plans of randomly selected patients to the study center

- Data entered into database will be checked independently by two physicians

\section{Ethics}

The trial protocol has been approved by the Ethics committee of the Saarland Physicians' Chamber (number 14/
07 on 09/05/2012). Furthermore, it has been approved by the board of directors of the DEGRO (German Society for Radiation Oncology).

\section{Accrual time}

Accrual of patients has begun in February, 2013 and is planned to last three years.

\section{Present status of the trial}

In the meantime 120 patients have been enrolled into study. The interim analysis is under discussion. Besides Saarland University Medical School, two further centers are actually enrolling patients.

\begin{abstract}
Abbreviations
AP-1: Activator protein-1; CCL: Chemocine ligand; cm: Centimeter(s); DEGRO: German Society for Radiation Oncology; GCGBD: German Cooperative Group for Radiotherapy for Benign Diseases; Gy: Gray; iNOS: Inducible nitric oxide synthetase; kV: Kilovolt; MR: Magnetic resonance; MV: Megavolt; NO: Nitric oxide; pH: Pondus hydrogenii; SF-12: Short Form-12; TGF $\beta 1$ : Transforming growth factor $\beta 1$; VAS: Visual analogue scale.
\end{abstract}

\section{Competing interests}

The authors declare that they have no competing interests.

\section{Authors' contributions}

$\mathrm{HH}$ wrote the manuscript based on the trial protocol. Furthermore, he is partially responsible for the patients' examinations and the data collection. $\mathrm{MN}$ is the principle investigator of this trial, corrected and approved the manuscript. He examines most of the patients and is responsible for data collection, quality assurance and evaluation. BP is partially responsible for the patients' examinations and the data collection. SG is responsible for the statistical evaluation of the data. CR supervised the radiotherapy and approved the manuscript.

\section{Acknowledgements}

The authors acknowledge M. Heinrich Seegenschmiedt, Oliver Micke, Ralf Muecke, Vera Schaefer, Christine Scheid, Jochen Fleckenstein, Norbert Licht, and the German Cooperative Group on Radiotherapy for Benign Diseases (GCGBD) of the German Society for Radiation Oncology (DEGRO) for the outstanding underlying trial. Without these data our present study could not exist [40].

\section{Author details}

${ }^{1}$ Department of Radiotherapy and Radiooncology, Saarland University Hospital, Kirrberger Str. 1, D-66421 Homburg, Germany. ${ }^{2}$ Department of Oral and Maxillofacial Surgery, University Hospital of Duesseldorf, Moorenstr. 5, D-40225 Duesseldorf, Germany. ${ }^{3}$ Institute of Medical Biometrics, Epidemiology and Medical Informatics, Saarland University Hospital, Kirrberger Str. 1, D-66421 Homburg, Germany.

Received: 27 February 2014 Accepted: 5 January 2015

Published online: 20 January 2015

References

1. Plettner P. Exostosen des Fersenbeins. Dresden: Jahresber Ges Natur Heilkunde; 1900

2. Seegenschmiedt MH, Keilholz L, Katalinic A, Stecken A, Sauer R. Heel spur: radiation therapy for refractory pain-results with three treatment concepts. Radiology. 1996;200:271-6.

3. Seegenschmiedt MH, Keilholz L, Stecken A, Katalinic A, Sauer R. Radiotherapy of plantar heel spurs: indications, technique, clinical results at different dose concepts. Strahlenther Onkol. 1996:172:376-83.

4. Heyd R, Uhder K, Straßmann G, Schneider L, Zamboglou N. Ergebnisse der analgetischen Radiotherapie bei inflammatorischen Fersensporn mit $6 \mathrm{MV}$ Photonen. Rontgenpraxis. 1996;52:26-32. 
5. Schreiber A, Zollinger H. Entzündungen/Fersenbeinsporne. In: Orthopädie in Klinik und Praxis Stuttgart: Thieme; 1985;441-445.

6. Gudeman SD, Eisele SA, Heidt RS, Colosimo AJ, Stoupe AL. Treatment of plantar fasciitis by iontophoresis of 0.4\% dexamethasone: a randomized double blind placebo controlled study. Amer J Sports Med. 1997;25:312-6.

7. Sistermann R, Katthagen BD. 5-years lithotripsy of plantar of plantar heel spur: experiences and results-a follow-up study after 36.9 months. Z Orthop Ihre Grenzgeb. 1998;136:402-6.

8. Batt ME. Plantar fasciitis: a prospective randomized clinical trial of the tension night splint. Clin J Sports Med. 1996;6:158-62.

9. Powell M, Post WR, Keener J, Wearden S. Effective treatment of chronic plantar fasciitis with dorsiflexion night splints: a crossover prospective randomized outcome study. Foot Ankle Int. 1998;19:10-8.

10. Pfeffer G. Comparison of custom and prefabricated ortheses in the initial treatment of proximal plantar fasciitis. Foot Ankle Int. 1999;20:214-21.

11. Turlik MA, Donatelli TJ, Veremis MG. A comparison of shoe inserts in relieving mechanical heel pain. Foot. 1999;9:84-7.

12. Crawford F, Atkins D, Edwards J. Interventions for treating plantar heel pain. The Cochrane Library 2001

13. Heider CC. Ergebnisse nach operativer Resektion von plantaren Fersenbeinspornen - eine retrospektive Studie. Orthopädische Universitätsklinik und Poliklinik Hamburg-Eppendorf. Hamburg 1998;40

14. Tomczak RL, Haverstock BD. Retrospective comparison of endoscopic plantar fasciotomy to open plantar fasciotomy with heel spur resection for chronic plantar fasciitis/heel spur syndrome. J Foot Ankle Surg. 1995;34:305-11.

15. Hoffman SJ, Thul JR. Fractures of the calcaneus secondary to heel spur surgery. An analysis and case report. J Am Podiatr Med Assoc. 1985;75:267-71.

16. Powell M, Post WR, Keener J, Wearden S. Biomechanical consequences of sequential plantar fascia release. Foot Ankle Int. 1998;19:149-52.

17. Basche S, Drescher W, Mohr K. Ergebnisse der Röntgenstrahlentherapie beim Fersensporn. Radiobiol Radiother. 1980;21:233-6.

18. Lindner $H$, Freislederer R. Langzeitergebnisse der Bestrahlung von degenerativen Skeletterkrankungen. Strahlenther Onkol. 1982;158:217-23.

19. Reichel WS. Die Röntgentherapie des Schmerzes. Strahlenther Onkol. 1949;80:483-534.

20. Zschache H. Ergebnisse der Röntgenschwachbestrahlung. Radiobiol Radiother. 1972;13:181-6.

21. Steffen C, Müller C, Stellamor K, Zeithofer J. Influence of X-ray treatment on antigen-induced experimental arthritis. Annals Rheum Dis. 1982;41:532-7.

22. Hildebrandt G, Seed MP, Freemantle CN, Alam CA, Colville-Nash PR, Trott KR. Mechanisms of the anti-inflammatory activity of low-dose radiation therapy. Int Journal Radiat Biol. 1998;74:367-78.

23. Hildebrandt G, Jahns J, Hindemith M, Spranger S, Sack U, Kinne RW, et al. Effects of low dose radiation therapy on adjuvant induced arthritis in rats. Int J Radiat Biol. 2000;76:1143-53.

24. Hildebrandt G, Seed MP, Freemantle CN, Alam CA, Colville-Nash PR, Trott KR. Effects of low dose ionizing radiation on murin chronic granulomatous tissue. Strahlenther Onkol. 1998;174:580-8.

25. Hildebrandt G, Loppnow G, Jahns J, Hindemith M, Anderegg U, Saalbach A, et al. Inhibition oft he iNOS pathway in inflammatory macrophages by low-dose X-irrdadiation in vitro. Strahlenther Onkol. 2003;179:158-66.

26. Rödel F, Kamprad F, Sauer R, Hildebrandt G. Funktionelle und molekulare Aspekte der anti-inflammatorischen Wirkung niedrig dosierter Radiotherapie. Strahlenther Onkol. 2002;178:1-9.

27. Hildebrandt G, Maggiorella L, Rödel F, Rödel V, Willis D, Trott KR. Mononuclear cell adhesion and cell adhesion molecule liberation after $X$-irradiation of activated endothelial cells in vitro. Int J Radiat Biol. 2002;78:315-25.

28. Gaipl US, Meister S, Lödermann B, Rödel F, Fietkau R, Herrmann M, et al. Activation-induced cell death and total Akt content of granulocytes show a biphasic course after low-dose radiation. Autoimmunity. 2009;42:340-2.

29. Roedel F, Hofmann D, Auer J, Keilholz L, Röllinghoff M, Sauer R, et al. The anti-inflammatory effect of low-dose radiation therapy involves a diminished CCL20 chemokine expression and granulocyte/endothelial cell adhesion. Strahlenther Onkol. 2008;184:41-7.

30. Roedel F, Keilholz L, Herrmann M, Weiss C, Frey B, Voll R, et al. Activator protein 1 shows a biphasic induction and transcrptional activity after low-dose X-irradiation in EA.hy.926 endothelial cells. Autoimmunity. 2008:42:343-5

31. Rödel F, Frey B, Gaipl US, Keilholz L, Fournier C, Manda K, et al. Modulation of Inflammatory Immune Reactions by Low-Dose lonizing Radiation: Molecular Mechanisms and Clinical Application. Curr Med Chem. 2012;19:1741-50.
32. Schaue D, Jahns J, Hildebrandt G, Trott K-J. Radiation treatment of acute inflammation in mice. Int J Radiat Biol. 2005;81:657-67.

33. Schaefer U, Micke O, Glashorster M, Rube C, Prott FJ, Willich N. The radiotherapy treatment of painful calcaneal spurs. Strahlenther Onkol. 1995:171:202-6.

34. Keim H. Mitteilung über die Durchführung der Entzündungsbestrahlung mit dem Telekobaltgerät. Strahlenther. 1965;127:49-52.

35. Mantell BS. The management of benign conditions. Radiotherapy in clinical practice. London: Butterworth's; 1986.

36. von Pannewitz G. Degenerative Erkrankungen. Berlin-Heidelberg-New York: Springer; 1965.

37. Goldie I, Rosengren B, Moberg E, Hedelin F. Evaluation of the radiation treatment of painful conditions of the locomotor system. Acta Radiol Ther Phys Biol. 1970;9:311-22.

38. Heyd R, Tselis N, Ackermann H, Röddiger SJ, Zamboglou N. Radiation therapy for painful heel spurs. Strahlenther Onkol. 2007;183:3-9.

39. Muecke R, Micke O, Reichl B, Heyder R, Prott FJ, Seegenschmiedt MH, et al. Demographic, clinical and treatment related predictors for event-free probability following low-dose radiotherapy for painful heel spurs - a retrospective multicenter study of 502 patients. Acta Oncol. 2007;46:239-46.

40. Niewald M, Seegenschmiedt MH, Micke O, Gräber S, Muecke B, Schaefer V, et al. Randomized multicenter trial on the effect of radiotherapy on plantar fasciitis (painful heel spur) using very low doses: mature results after 12 months follow-up. Int J Radiat Oncol Biol Phys. 2012;84:e455-62.

41. Ott OJ, Jeremias C, Gaipl US, Frey B, Schmidt M, Fietkau R. Radiotherapy for benign calcaneodynia: long-termin results oft the Erlangen Dose Optimization (EDO) trial. Strahlenther Onkol. 2014;190:671-5.

42. Mitrov G, Harbov I. Unsere Erfahrungen mit der Strahlentherapie von nichttumorartigen Erkrankungen. Radiobiol Radiother. 1967;8:419.

43. Sautter-Biehl ML, Liebermeister E, Scheurig H, Heinze HG. Analgetische Bestrahlung degenerativ-entzündlicher Skeletterkrankungen. Dtsch Med Wschr. 1993;118:493-8.

44. Gaertner C, Schuettauf M, Below M, Motorina LI, Michina ZP. Zur strahlentherapeutischen Behandlung chronisch-rezidivierender Skelettveränderungen an der Klinik für Osteologie (Charité). Radiobiol Radiother. 1988;29:687-96.

45. Fuchs G. Die Strahlenbelastung der Gonaden in der Röntgentherapie. Strahlenther Onkol. 1960;111:297-300.

46. Schuhmann E, Lademann W. Zur Gonadenbelastung bei der Strahlentherapie nicht-tumoröser Erkrankungen. Radiobiol Radiother 1965;6:455-7.

47. Micke O. Seegenschmiedt MH: SF36/SF12 - Werkzeuge zur Evaluation der Lebensqualität bei der Strahlentherapie von degenerativen Erkrankungen. In: Radiotherapie bei gutartigen Erkrankungen - 15. Kolloquium Radioonkologie/Strahlentherapie, Essen, 2000 Edited by: Seegenschmiedt MH, Makoski B. Altenberge: Diplodocus Verlag; 2001;51-64

48. Bullinger M, Morfeld M, Kohlmann T, Nantke J, van den Bussche H, Dodt B, et al. Der SF-36 in der rehabilitationswissenschaftlichen Forschung - Ergebnisse aus dem Norddeutschen Verbund für Rehabilitationsforschung (NVRF) im Förderschwerpunkt Rehabilitationswissenschaften. Rehabilitation. 2003;42:218-25.

49. Rowe C, Sakellarides HT, Freeman PA, Sorbie C. Fractures of the os calcis. JAMA. 1963;184:920-3.

\section{Submit your next manuscript to BioMed Central and take full advantage of:}

- Convenient online submission

- Thorough peer review

- No space constraints or color figure charges

- Immediate publication on acceptance

- Inclusion in PubMed, CAS, Scopus and Google Scholar

- Research which is freely available for redistribution 